\title{
The effect of dexmedetomidine and clonidine on the inflammatory response in critical illness: a systematic review of animal and human studies
}

\author{
Charles A. Flanders ${ }^{1+} \mathbb{D}$, Alistair S. Rocke ${ }^{1 \dagger}$, Stuart A. Edwardson ${ }^{2}$, J. Kenneth Baillie ${ }^{1}$ and Timothy S. Walsh ${ }^{1,2,3^{*}}$
}

\begin{abstract}
Background: The a2 agonists, dexmedetomidine and clonidine, are used as sedative drugs during critical illness. These drugs may have anti-inflammatory effects, which might be relevant to critical illness, but a systematic review of published literature has not been published. We reviewed animal and human studies relevant to critical illness to summarise the evidence for an anti-inflammatory effect from a2 agonists.

Methods: We searched PubMed, the Cochrane library, and Medline. Animal and human studies published in English were included. Broad search terms were used: dexmedetomidine or clonidine, sepsis, and inflammation. Reference lists were screened for additional publications. Titles and abstracts were screened independently by two reviewers and full-text articles obtained for potentially eligible studies. Data extraction used a bespoke template given study diversity, and quality assessment was qualitative.

Results: Study diversity meant meta-analysis was not feasible so descriptive synthesis was undertaken. We identified 30 animal studies (caecal ligation/puncture (9), lipopolysaccharide (14), acute lung injury (5), and ischaemia-reperfusion syndrome (5)), and 9 human studies. Most animal (26 dexmedetomidine, 4 clonidine) and all human studies used dexmedetomidine. In animal studies, a2 agonists reduced serum and/or tissue TNFa (20 studies), IL-6 (17 studies), IL-1 3 (7 studies), NFKB (6 studies), TLR4 (6 studies), and a range of other mediators. Timing and doses varied widely, but in many cases were not directly relevant to human sedation use. In human studies, dexmedetomidine reduced CRP (4 studies), TNFa (5 studies), IL-6 (6 studies), IL-1 $\beta$ (3 studies), and altered several other mediators. Most studies were small and low quality. No studies related effects to clinical outcomes.

Conclusion: Evidence supports potential anti-inflammatory effects from a2 agonists, but the relevance to clinically important outcomes is uncertain. Further work should explore whether dose relationships with inflammation and clinical outcomes are present which might be separate from sedation-mediated effects.
\end{abstract}

Keywords: Dexmedetomidine, Clonidine, Inflammation, Sepsis, Immune system, Critical care

\footnotetext{
* Correspondence: Timothy.Walsh@ed.ac.uk

Charles A Flanders and Alistair S Rocke are joint first authors.

${ }^{\dagger}$ Charles A. Flanders and Alistair S. Rocke contributed equally to this work.

${ }^{1}$ Critical Care Department, Royal Infirmary of Edinburgh, Edinburgh, UK

${ }^{2}$ Department of Anaesthesia, Critical Care and Pain Medicine, University of

Edinburgh, Edinburgh, UK

Full list of author information is available at the end of the article
}

(c) The Author(s). 2019 Open Access This article is distributed under the terms of the Creative Commons Attribution 4.0 International License (http://creativecommons.org/licenses/by/4.0/), which permits unrestricted use, distribution, and reproduction in any medium, provided you give appropriate credit to the original author(s) and the source, provide a link to the Creative Commons license, and indicate if changes were made. The Creative Commons Public Domain Dedication waiver (http://creativecommons.org/publicdomain/zero/1.0/) applies to the data made available in this article, unless otherwise stated. 


\section{Background}

The $\alpha 2$ agonists dexmedetomidine and clonidine are widely used as sedative drugs during critical illness, acting by dosedependent decrease in activity of noradrenergic neurons in the brain stem via post-synaptic receptor-mediated inhibition [1]. This increases gamma-aminobutyric acid (GABA) neurone activity, which mediates central sedative effects. Dexmedetomidine, a highly selective $\alpha 2$ agonist ( $\alpha 2: \alpha 1$ receptor selectivity ratio 1620:1), is licenced for intensive care unit (ICU) sedation and systematic reviews suggest it decreases duration of mechanical ventilation and ICU stay compared with propofol and/or benzodiazepines [2-4]. Effects on delirium are less certain [2, 4], but recent trials suggest dexmedetomidine can decrease delirium in selected populations, even when used in low doses [5]. Clonidine has substantially lower $\alpha 2: \alpha 1$ selectivity (220:1), is unlicensed for ICU sedation, but is also widely used in some countries. Despite this popularity, evidence for clinical effectiveness is very limited and of poor quality [6].

$\alpha 2$ agonists decrease central sympathetic nerve activity, which might affect inflammation and immune function either directly via cell surface receptors or indirectly by altering sympathetic/parasympathetic balance [7-9]. Although $\alpha 2$ agonists cause bradycardia, they may paradoxically increase cardiovascular stability in shock [10-12]. A post hoc trial analysis [13] and prospective clinical trial [14] suggest trends towards improved survival in sepsis when dexmedetomidine is used for sedation but remains unproven and was not observed in the recent large SPICE III randomised trial [15].

If $\alpha 2$ agonists have effects via mechanisms other than sedation, these could be important for clinical practice. Any anti-inflammatory effects could plausibly explain putative effects on delirium, shock, and other organ dysfunction and might explain why low doses of dexmedetomidine decrease delirium in perioperative patients [16]. Current evidence for anti-inflammatory effects from $\alpha 2$ agonists in critical illness has not previously been summarised. We therefore undertook a systematic review of relevant animal and human studies of critical illness to summarise current evidence.

\section{Methods}

\section{Inclusion criteria}

Eligible studies were animal or human studies undertaken in the context of sepsis, inflammation, or both. We limited studies to those that included dexmedetomidine or clonidine. All included studies required a biological measure of the inflammatory response as an outcome.

\section{Search}

We searched PubMed, the Cochrane library, and Medline in accordance with the PRISMA guidelines; the
PRISMA checklist is available as an Additional file 1. The final search was done on May 14, 2019. Search terms used were broad: dexmedetomidine, sepsis and inflammation; and clonidine, sepsis and inflammation. We had no date limits but included only studies published in English. Reference lists were screened for additional publications. After removing duplicates, titles and abstracts were screened independently by two reviewers (CAF and ASR) and full-text articles obtained wherever possible for all potentially eligible studies. Disagreements were resolved between the two reviewers, with reference to the senior author (TSW). Full-text articles were retrieved from the National Health Service, Athens, Knowledge Network, University of Edinburgh, and the British Library. Where a full-text article was unavailable and there was insufficient information in the abstract to determine eligibility, it was excluded.

For eligible studies, data were extracted into a table that summarised: type of study (animal, human), population, interventions used and comparators, outcomes, key summary findings, and any relevant additional comments or findings (see Additional files 2, 3, 4 and 5).

We grouped studies as follows:

\section{Animal studies}

Sepsis models (caecal ligation and puncture (CLP), and lipopolysaccharide (LPS)), acute lung injury models (ALI), and ischaemia/reperfusion injury (IRI) models.

\section{Human studies}

Any human study involving perioperative and/or critically ill patients fulfilling inclusion criteria.

As the type and range of studies varied widely and were mostly animal models, we did not undertake formal quality assessment using an existing tool. Instead, we documented potentially important limitations qualitatively for each study. Evidence synthesis was descriptive, because data were not suitable for meta-analysis.

\section{Results}

The search identified 188 records; manual reference searching identified an additional 21 records. After removing duplicates 140 study abstracts were screened, and 95 selected for full text analysis. After full text review, 53 articles did not meet inclusion criteria and 42 articles were included in the review. The PRISMA flowchart is shown in Fig. 1. We identified 33 animal studies (9 CLP, 14 LPS, 5 ALI, 5 IRI) and 9 human studies.

\section{Animal studies}

The key inflammatory molecules tested are described in Table 1 with a summary of all animal studies in Additional file 2 and a detailed description in Additional file 3. 


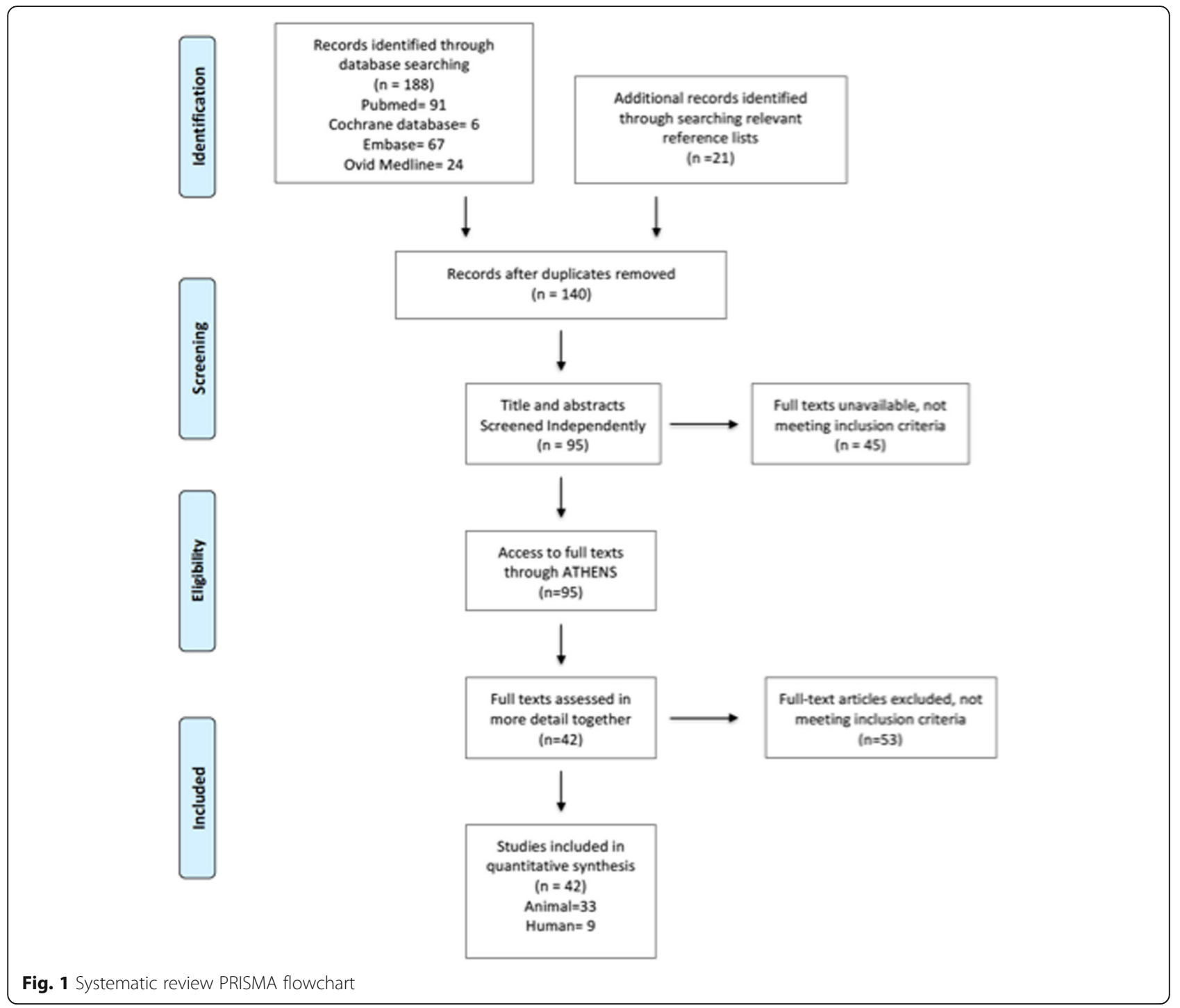

\section{Caecal ligation and puncture (CLP)}

The nine CLP models were undertaken in rats [17, 21-23, 34, 41, 42] and mice [36, 37]. Seven studies used dexmedetomidine $[17,22,23,34,36,37,41$, 42] and one clonidine [21]. Study size ranged from 21 to 210 animals with a range of control group designs. Routes of administration were intraperitoneal $[22,36,41,42]$ and intravenous [17, 21, 23, 34, 37] as well as bolus [21-23, 36, 37, 41, 42] versus infusion $[17,34]$. Study design included pre-only groups $[34,42]$, pre/post groups $[21,36]$, and post-only [17, $22,23,37,41]$ designs. Three studies included $\alpha 2$ agonist blockade groups [17, 23, 42]. A range of dexmedetomidine doses was used but in most studies was high compared to human sedative doses. Duration of experiments varied widely (6h to 7 days), but most were less than $24 \mathrm{~h}$ with widely varying sampling schedules.
Hofer et al. found both high dose intraperitoneal clonidine $(5 \mu \mathrm{g} / \mathrm{kg})$ and dexmedetomidine $(40 \mu \mathrm{g} / \mathrm{kg})$ decreased NFKB and pro-inflammatory cytokines (TNF $\alpha$, IL-1 $\beta$, IL-6) and improved survival [21], with effects most marked with pre-CLP administration. Qiao et al. found dexmedetomidine $(5 \mu \mathrm{g} / \mathrm{kg} / \mathrm{h}$ infusion) reduced Tumour necrosis factor alpha (TNFa), Interleukin-6 (IL6), and caspase-3 but found similar effects from midazolam [34]. Wu et al. found higher doses of intraperitoneal dexmedetomidine (range $10-20 \mu \mathrm{g} / \mathrm{kg}$ ) reduced inflammatory response within the lungs (bronchoalveolar lavage [BAL] TNFo, IL-6; lung tissue Toll-like receptor 4 (TLR4), Myeloid differentiation primary response 88 (MyD88), and NFkB) and improved survival [22]. Xu et al. found intravenous dexmedetomidine bolus $(40 \mu \mathrm{g} /$ $\mathrm{kg}$ ) decreased TNF $\alpha$ and IL-6, with greatest effects after $24 \mathrm{~h}$, and improved survival. Effects were greatest with pre-CLP dexmedetomidine administration [36]. Koca 
Table 1 Inflammatory molecules tested in animal studies

\begin{tabular}{lll}
\hline Animal studies & & \\
\hline Inflammatory molecule & Alteration with a2 agonist & Location \\
\hline Myeloperoxidase & Decreased & Lung tissue \\
& & Bronchoalveolar lavage fluid \\
Nuclear factor Kappa B & Epigastric skin tissue flap \\
& Decreased & Lung tissue \\
& & Bronchoalveolar lavage fluid
\end{tabular}

Nitric Oxide/inducible nitric oxide synthase mRNA

Tumour Necrosis Factor- a

Interleukin-6

Toll-like Receptor 4
Decreased

Decreased

Decreased

Decreased

Decreased
Lung tissue

Serum

Epigastric skin tissue flap

Lung tissue

Bronchoalveolar lavage fluid Serum

Myocardial tissue

Lung tissue

Bronchoalveolar lavage fluid Serum

Myocardial tissue
Citation

Chen et al. [17]

Jiang et al. [18]

Uysal et al. [19]

Chen et al. [17]

Kong et al. [20]

Hofer et al. [21]

Wu et al. [22]

Zhang et al. [23]

Shen et al. [24]

Chen et al. [17]

Yang et al. [25]

Yang et al. [26]

Sugita et al. [27]

Uysal et al. [19]

Jiang et al. [18]

Loftus et al. [28]

Yang et al. [26]

Chen et al. [3]

Kang et al. [29]

Kong et al. [20]

Tan et al. [30]

Taniguchi et al. [31]

Taniguchi et al. [32]

Xiang et al. [33]

Chen et al. [17]

Hofer et al. [21]

Qiao et al. [34]

Wu et al. [22]

Feng et al. [35]

Xu et al. [36]

Zhang et al. [23]

Shen et al. [24]

Sugita et al. [27]

Zhang et al. [4]

Jiang et al. [18]

Yang et al. [25]

Chen et al. [17]

Kong et al. [20]

Tan et al. [30]

Feng et al. [35]

Taniguchi et al. [31]

Taniguchi et al.

Xiang et al. [32]

Chen et al. [3]

Hofer et al. [21]

Kang et al. [29]

Qiao et al. [34]

Zhang et al. [37]

Wu et al. [22]

Xu et al. [36]

Zhang et al. [23]

Shen et al. [24]

Sugita et al. [27]

Zhang et al. [4]

Jiang et al. [18]

Chen et al. [17]

Wu et al. [22]

Zhang et al. [23]

Shen et al. [24]

Zhang et al. [4]

Jiang et al. [18]

Wu et al. [22]

Zhang et al. [23] 
Table 1 Inflammatory molecules tested in animal studies (Continued)

\begin{tabular}{|c|c|c|c|}
\hline \multicolumn{4}{|l|}{ Animal studies } \\
\hline \multirow{2}{*}{ Inflammatory molecule } & Alteration with a2 agonist & Location & Citation \\
\hline & & & Zhang et al. [4] \\
\hline Interleukin-10 & Decreased & Serum & Szelenyi et al. [38] \\
\hline Vascular endothelial growth factor & Increased & Lung tissue & Loftus et al. [28] \\
\hline Vascular endothelial growth factor receptors 1 and 2 & Increased & Lung tissue & Loftus et al. [28] \\
\hline Interleukin-1b & Decreased & $\begin{array}{l}\text { Lung tissue } \\
\text { Serum } \\
\text { Myocardial tissue }\end{array}$ & $\begin{array}{l}\text { Yang et al. [25] } \\
\text { Yang et al. [26] } \\
\text { Kong et al. [20] } \\
\text { Zhang et al. [37] } \\
\text { Xiang et al. [33] } \\
\text { Feng et al. [35] } \\
\text { Chen et al. [17] } \\
\text { Hofer et al. [21] }\end{array}$ \\
\hline A-7 nicotinic acetylcholine receptor & Increased & Myocardial tissue & Kong et al. [20] \\
\hline Organic hyperoxides and superoxide radicals & Decreased & $\begin{array}{l}\text { Lung tissue } \\
\text { Hepatic tissue } \\
\text { lleal tissue }\end{array}$ & $\begin{array}{l}\text { Chen et al. [17] } \\
\text { Filos et al. [39] }\end{array}$ \\
\hline High Mobility Group Box 1 (HMGB1) & Decreased & $\begin{array}{l}\text { Lung tissue } \\
\text { Renal tissue } \\
\text { Myocardial tissue } \\
\text { Serum }\end{array}$ & $\begin{array}{l}\text { Loftus et al. [28] } \\
\text { Tan et al. [30] } \\
\text { Xu et al. [36] } \\
\text { Zhang et al. [4] }\end{array}$ \\
\hline Kidney Injury Molecule 1(KIM1) & Decreased & Renal tissue & Tan et al. [30] \\
\hline B-Actin & Decreased & Serum & Yang et al. [25] \\
\hline Cyclo-oxygenase 2 (COX-2) & Decreased & Serum & $\begin{array}{l}\text { Yang et al. [25] } \\
\text { Yang et al. [26] }\end{array}$ \\
\hline Prostaglandin E2 (PGE2) & Decreased & Serum & Yang et al. [26] \\
\hline Macrophage inflammatory protein 2 (MIP2) & Decreased & Serum & Yang et al. [26] \\
\hline Lactate & Decreased & Serum & $\begin{array}{l}\text { Chen et al. [17] } \\
\text { Miranda et al. [40] } \\
\text { Chen et al. [3] }\end{array}$ \\
\hline Malondialdehyde (MDA) & Decreased & $\begin{array}{l}\text { Renal tissue } \\
\text { Epigastric skin tissue flap }\end{array}$ & $\begin{array}{l}\text { Chen et al. [3] } \\
\text { Koca et al. [41] } \\
\text { Uysal et al. [19] }\end{array}$ \\
\hline
\end{tabular}

et al. found intraperitoneal dexmedetomidine $(50 \mu \mathrm{g} / \mathrm{kg}$ post-CLP) decreased acute kidney injury (histology, creatinine, and Neutrophil gelatinase-associated lipocalin (NGAL)) and inflammatory markers (Cytokeratin 18 (CK18); M30) $6 \mathrm{~h}$ post-injury [41]. Zhang et al. found intravenous dexmedetomidine ( $5 \mathrm{or} 10 \mu \mathrm{g} / \mathrm{kg}$ bolus postCLP) attenuated all measured inflammatory markers (TNF $\alpha$, IL-6, TLR4, MyD88, and NFKB) 6 h post-injury, but effects were not reduced by yohimbine [23]. Chen et al. found intravenous dexmedetomidine $(5 \mu \mathrm{g} / \mathrm{kg}$ over $1 \mathrm{~h}$ ) attenuated all inflammatory markers (TNFo, Interleukin-1 $\beta$ (IL-1 $\beta)$, IL-6, TLR4) and lactate production when delivered $30 \mathrm{~min}$ post-CLP, and improved survival; these effects were partially prevented by yohimbine [17]. Zhang et al. found intravenous dexmedetomidine at various doses $(0.1,0.3,0.5 \mathrm{mg} / \mathrm{kg})$ given $30 \mathrm{~min}$ post-CLP improved serum IL-6 and IL-1 $\beta$ [37]. Finally, Zhang et al. found dexmedetomidine $(10 \mu \mathrm{g} / \mathrm{kg}) \mathrm{im}-$ proved survival and histological lung injury scores (including tissue caveolin-1 expression), with effects partially reversed by the antagonist APZ [43].

\section{Lipopolysaccharide (LPS) administration}

The 14 LPS models were undertaken in rats [30-33, 35, 44-47], mice [20, 29, 38, 48], and hamsters [40]. Thirteen studies used dexmedetomidine [20, 22, 29-33, 35, 40, 44-47] and one clonidine [38]. Study size ranged from 40 to 104 animals. Design varied widely and included pre-LPS only [20, 29, 30, 32, 33, 35, 38], postLPS only [31, 40, 44-46, 48], and at initiation of LPS [47]. LPS was administered intravenously in all studies. Five studies [29, 30, 35, 38, 44] included comparison with $\alpha 2$ antagonist treatment. Doses (2.5 to $50 \mu \mathrm{g} / \mathrm{kg}$ ) and duration of experiments (range 3 to $20 \mathrm{~h}$ ) varied widely but most were short duration.

Taniguchi et al. found intravenous dexmedetomidine $5 \mu \mathrm{g} / \mathrm{kg} / \mathrm{h}$ post-LPS decreased TNF $\alpha$ and IL-6, improved survival, and decreased lung neutrophil infiltration over 
$8 \mathrm{~h} \mathrm{[31].} \mathrm{A} \mathrm{further} \mathrm{study} \mathrm{described} \mathrm{dose-dependent} \mathrm{re-}$ duction (dexmedetomidine 2.5 to $10 \mu \mathrm{g} / \mathrm{kg} / \mathrm{h}$ ) in $\mathrm{TNF} \alpha$ and IL- 6 over $5 \mathrm{~h}$ when started pre-LPS administration; effects were absent with lowest doses, and post-LPS administration had less marked effects [32]. Sezer et al. found intravenous dexmedetomidine $5 \mu \mathrm{g} / \mathrm{kg} / \mathrm{h}$ decreased histological markers of inflammation $8 \mathrm{~h}$ postLPS [45]. Shi et al. administered three boluses of dexmedetomidine $(0.5,1.5$, and $4.5 \mu \mathrm{g} / \mathrm{kg})$ and found lung TNF $\alpha$, IL-6, IL-1 $\beta$, TLR4, NFKB, and lung wet/dry ratios were all decreased with the two higher (but not the lowest) dexmedetomidine doses [46]. Kong et al. found dexmedetomidine administered as a $10 \mathrm{mg} / \mathrm{kg}$ bolus $1 \mathrm{~h}$ prior to LPS reduced myocardial apoptosis, NFkB, IL-6, and IL-1 $\beta$ and was attenuated by $\alpha$-bungarotoxin (ABT), an antagonist at the $\alpha-7$ nicotinic acetylcholine receptor [20]. Szelenyi et al. found intraperitoneal clonidine (5 $\mathrm{mg} / \mathrm{kg}$ ), administered $30 \mathrm{~min}$ prior to LPS, significantly reduced Interleukin-10 (IL-10) and was reversed when $\alpha 2$ antagonists (CH- 38083, WB04101, Prazosin) were administered [38]. Yeh et al. found intravenous dexmedetomidine $(5 \mu \mathrm{g} / \mathrm{kg} / \mathrm{h})$ administered concurrently with LPS showed no harmful effect on cardiovascular parameters and reduced small bowel markers of endothelial dysfunction [47]. Wu et al. found dexmedetomidine 5 and $50 \mu \mathrm{g} / \mathrm{kg} / \mathrm{h}$ infusion for $8 \mathrm{~h}$ from LPS administration attenuated $\mathrm{T}$ and $\mathrm{B}$ cell production, reduced macrophage phagocytosis at both doses, and increased NK cell activity at the high dexmedetomidine dose [48]. Xiang et al. administered dexmedetomidine $40 \mu \mathrm{g} / \mathrm{kg}$ as a bolus pre-LPS and found attenuation of TNF $\alpha$, IL- 6 , and IL- $1 \beta$ and improved survival; effects were reversed by administration of the $\alpha 2$ antagonist ABT [33]. Chen et al. found intravenous dexmedetomidine $5 \mu \mathrm{g} / \mathrm{kg} / \mathrm{h}$ attenuated a range of blood and liver inflammatory/injury markers, which was attenuated by yohimbine [44]. Miranda et al. used a skinfold chamber technique to study microcirculation in a hamster LPS model of dexmedetomidine $5 \mu \mathrm{g} / \mathrm{kg} / \mathrm{h} 1 \mathrm{~h}$ post-LPS, finding no difference in vasodilatation, but a reduction in leukocyte rolling following dexmedetomidine [40]. Feng et al. administered dexmedetomidine at $25 \mu \mathrm{g} / \mathrm{kg}$ as a bolus pre-LPS and found attenuation of TNF $\alpha$, IL- 6 , IL-8, and IL- $1 \beta$. This effect was reversed when administered with ATZ [35]. Kang et al. found that dexmedetomidine administered at $40 \mu \mathrm{g} / \mathrm{kg}$ attenuated serum TNF $\alpha$ and IL-6 when given 1-h pre-LPS induced acute kidney injury. This effect was reversed when administered with the $\alpha 2$ antagonist ABT [29]. Finally, Tan et al. observed a decrease in TNF $\alpha$, IL-6, Interleukin-8 (IL-8), and in renal High mobility group protein B1 (HMGB1) expression following pre-LPS dexmedetomidine $10 \mu \mathrm{g} / \mathrm{kg}$ administration, which was attenuated by concurrent yohimbine administration [30].

\section{Acute lung injury models}

Five studies were undertaken in rats $[18,25,26,28]$ and dogs [49]. Four used dexmedetomidine [18, 25, 26, 49] and one clonidine [28]. Study size ranged from 30 to 84 animals. The ALI model was ventilator-induced lung injury (VILI) [25, 26, 49], ischaemia [18], and trauma [28]. Two studies $[18,25]$ included $\alpha 2$ agonist blockade groups. The dose varied widely 0.5 to $5 \mu \mathrm{g} / \mathrm{kg} / \mathrm{h}$ dexmedetomidine and duration of experiments from $4 \mathrm{~h}$ to 7 days.

Yang et al. used a rat VILI model (10 versus $20 \mathrm{~mL} / \mathrm{kg}$ ) and compared effects from $0.5,2.5$, and $5 \mu \mathrm{g} / \mathrm{kg}$ dexmedetomidine. Lung histology studies and expression of TNF $\alpha$, IL-1 $\beta$, IL-6, macrophage inflammatory protein 2 (MIP-2), Nitric Oxide (NO), Prostaglandin E2 (PGE2), Nitric oxide synthase (iNOS), Cyclooxygenase 2 (COX2), and $\beta$-actin showed only the $5 \mu \mathrm{g} / \mathrm{kg}$ dose attenuated inflammation; the effect was attenuated by yohimbine [25]. In a further study, this group found intravenous dexmedetomidine at lower dose $(0.5 \mu \mathrm{g} / \mathrm{kg} / \mathrm{h})$ reduced VILI in an LPS-plusVILI model, based on histology and pro-inflammatory markers [26]. Chen et al. induced VILI in dogs $(20 \mathrm{~mL} /$ $\mathrm{kg}$ ), studied three intravenous dexmedetomidine doses from intubation $(0.5,1.0$, and $2.0 \mu \mathrm{g} / \mathrm{kg} / \mathrm{h})$, and examined lung injury at $4 \mathrm{~h}$. They found dose-dependent reduction in lung TNF $\alpha$, iNOS, NFKB, and BAL Myeloperoxidase (MPO) and Polymorphonuclear neutrophils (PMN), with increasing dexmedetomidine dose [49]. Jiang et al. studied pre-injury dexmedetomidine ( 2.5 and $5 \mu \mathrm{g} / \mathrm{kg} / \mathrm{h}$ ) effects in an ischaemia (hilar occlusion) model of ALI in rats, finding dexmedetomidine reduced lung injury scores and inflammatory markers (MPO, TNFo, IL-6, TLR4, MyD88, Phospho-JNK, and Phospho-ERK); yohimbine partially reversed effects on some injury markers [18]. Finally, Loftus et al. used a complex trauma model including haemorrhage, lung contusion, and stress over 7 days to explore the effects of clonidine $(10 \mu \mathrm{g} / \mathrm{kg})$ on lung injury, finding high doses of clonidine increased vascular endothelial growth factor (VEGF) and its receptor expression in the lungs [28].

\section{Ischaemia-reperfusion injury (IRI) models}

The five studies were all in rats, four dexmedetomidine $[19,24,27,43]$ and one clonidine [39]. Study size ranged from 30 to 80 animals. Two studies $[24,43]$ included $\alpha 2$ agonist blockade groups. Doses varied widely 0.5 to $5 \mu \mathrm{g} / \mathrm{kg} / \mathrm{h}$ dexmedetomidine, as did duration of experiments ( $4 \mathrm{~h}$ to 7 days).

Filos et al. used a haemorrhage model and studied the effects of clonidine pre-treatment $(150 \mu \mathrm{g} / \mathrm{kg}$ subcutaneously) on circulating endotoxin and tissue superoxide radicals, finding both were reduced [39]. Uysal et al. used a femoral artery/vein clamp model to study effects of dexmedetomidine 10 and $30 \mu \mathrm{g} / \mathrm{kg}$ on an epigastric 
island skin flap $12 \mathrm{~h}$ and 7 days post-IRI finding both doses reduced tissue NO, MDA, and MPO at both time points, and reduced flap necrosis area [19]. Shen et al. used a superior mesenteric artery occlusion model to study effects of dexmedetomidine 2.5 and $5 \mu \mathrm{g} / \mathrm{kg} / \mathrm{h}$ infusion pre-IRI on lung injury, finding dose-dependent reductions in lung TLR4 and MyD88 (but not phosphoinositide 3-kinase (Pi3k) or Protein kinase B (AKT)) and improved lung histology and wet/dry weight ratio, with effects unaltered by yohimbine [24]. Sugita et al. studied effects of dexmedetomidine 10 and $20 \mu \mathrm{g} / \mathrm{kg} / \mathrm{h}$ from the time of reperfusion on circulating TNF $\alpha$, IL-6, IL-6, and NOS, finding attenuation of IL- 6 and iNOS, but not TNF $\alpha$, Endothelial derived nitric oxide (eNOS), or Neuronal nitric oxide (nNOS) $6 \mathrm{~h}$ post-IRI [27]. Finally, Zhang et al. studied the effects of dexmedetomidine infusion on myocardial injury in a coronary occlusion model, finding a reduction in infarct size and all measures of myocardial inflammation studied; this effect was attenuated by yohimbine [43].

\section{Human studies}

We identified nine randomised controlled studies in humans. The populations were elective one-lung ventilation [50], laparoscopic cholecystectomy [51, 52], abdominal surgery [53, 54], spinal fusion surgery [55], cardiac surgery [56], and sepsis [14, 57]. All studies used dexmedetomidine; none used clonidine. Comparator treatments varied, comprising a control/placebo [50-52, 55, 56], propofol [14, 53, 54], and midazolam [57]. Size ranged from 20 to 201 patients; eight studies had a total size $<50$ patients. Dexmedetomidine timing and dose varied: single bolus [50], in seven [51-57] as a bolus (range 0.5 to $2.5 \mu \mathrm{g} / \mathrm{kg}$ ) followed by an infusion (range 0.5 to $2.5 \mu \mathrm{g} / \mathrm{kg} /$ h), and titration to a sedation target [14].

$C$ Reactive Protein (CRP) was measured in four studies $[14,51,55,56]$ and was decreased in all studies compared to the comparator. TNF $\alpha$ was measured in five studies $[50,51,53,55,57]$ and was reduced in all studies compared to the comparator. IL-6 was measured in six studies [51, 53-57]; dexmedetomidine decreased IL-6 in four studies [53, 55-57], but in two $[51,54]$ no difference was detected. IL- $1 \beta$ was measured in three studies [51, 53, 57] and was decreased in all studies. Other findings included a reduction in IL-10 [51], a transient attenuation of NFKB [56], an increase in the interferon/IL-4ratio [52], a decrease in CD42a/CD14 ratio and an increase in Human leukocyte antigen-DR isotype (HLA-DR)/CD14 ratio with dexmedetomidine [55]. The key inflammatory molecules tested are described in Table 2 with a summary of each study in Additional file 4 and a detailed description in Additional file 5.

\section{Discussion}

We found both animal and human studies supported antiinflammatory effects from the $\alpha 2$ agonists used in treatment of critically ill humans, namely dexmedetomidine and clonidine. However, only four animal and no human evaluated the effects of clonidine. There was wide variability in animal study design, but overall results were consistent with a reduction in markers of inflammation and organ injury. Anti-inflammatory effects were also observed in most human studies [14, 50, 51, 53, 55-57].

Animal studies were heterogeneous in design in relation to the stimulus (LPS, CLP, IRI, and VILI), route of administration and timing of $\alpha 2$ agonist, and dose regimen used. There was variation in the biological/pathological marker of inflammation used, but effects on pro-inflammatory cytokines were broadly consistent across studies. Studies using antagonists $[4,18,20,25,29,30,33,35,38,44]$ mostly suggested attenuation or elimination of effects, supporting a receptor-mediated mechanism, but this was not universal. The relevance of the animal studies to human disease is uncertain, especially because doses were mostly significantly higher than licenced for human use. No study measured plasma drug concentrations. Although the relevance to established critical illness of pre-insult administration is uncertain, this might be relevant to perioperative administration during major surgery. The coadministration of drugs such as ketamine in some studies $[21,26]$ might also interact with $\alpha 2$ agonist pathways, limiting relevance to human disease. Few studies measured concurrent cardiovascular responses [21, 27, 31, 32, 47], which are potentially important side effects in humans, and almost all studies were undertaken in small animals, which may not be relevant models to human inflammatory disease. The consistency of reported effects across studies supports potentially relevant modulation of inflammation and/or immune responses. However, we cannot exclude an influence from publication bias.

Of the nine human studies, only two were undertaken in critically ill patients with sepsis or other clear inflammatory conditions [14, 57]; the remainder included elective surgical populations [20, 50, 52-56]. Most studies performed serum cytokine assays until around $48 \mathrm{~h}$ post-operatively and observed reductions compared with control patients in the immediate post-operative period. The main study limitations were small sample size and the uncertain relevance of inflammatory mediator concentrations to clinical outcomes. All of the 9 human studies used dexmedetomidine. The largest study was undertaken in mechanically ventilated septic patients and had non-significantly different clinical primary outcomes (mortality and ventilation-free days). Dexmedetomidine doses were smaller than those widely used for clinical sedation $(0.1-0.7 \mu \mathrm{g} / \mathrm{kg} / \mathrm{h})$, but despite this the observed reduction in CRP concentrations is consistent 
Table $\mathbf{2}$ Inflammatory molecules tested in human studies

\begin{tabular}{|c|c|c|c|}
\hline \multicolumn{4}{|l|}{ Human studies } \\
\hline Inflammatory molecule & Alteration with a2 agonist & Location & Citation \\
\hline Interferon Gamma & Increased & Serum & Kim et al. [52] \\
\hline Tumour Necrosis Factor- a & Decreased & Serum & $\begin{array}{l}\text { Gao et al. [50] } \\
\text { Kang et al. [51] } \\
\text { Memis et al. [57] } \\
\text { Tasdogan et al. [53] } \\
\text { Zhou et al. [55] }\end{array}$ \\
\hline Superoxide Dismutase & Decreased & Serum & Gao et al. [50] \\
\hline Malondialdehyde & Decreased & Serum & Gao et al. [50] \\
\hline Heme-oxygenase 1 & Decreased & Lung tissue & Gao et al. [50] \\
\hline White Cell count & Decreased & Serum & $\begin{array}{l}\text { Kang et al. [51] } \\
\text { Zhou et al. [55] }\end{array}$ \\
\hline Interleukin-1b & Decreased & Serum & $\begin{array}{l}\text { Kang et al. [51] } \\
\text { Memis et al. [57] } \\
\text { Tasdogan et al. [53] }\end{array}$ \\
\hline Interleukin-6 & Decreased & Serum & $\begin{array}{l}\text { Kang et al. [18] } \\
\text { Memis et al. [57] } \\
\text { Tasdogan et al. [53] } \\
\text { Ueki et al. [56] } \\
\text { Venn et al. [54] } \\
\text { Zhou et al. [55] }\end{array}$ \\
\hline Interleukin-10 & Decreased & Serum & $\begin{array}{l}\text { Kang et al. [51] } \\
\text { Zhou et al. [55] }\end{array}$ \\
\hline C Reactive Protein & Decreased & Serum & $\begin{array}{l}\text { Kang et al. [51] } \\
\text { Kawazoe et al. [14] } \\
\text { Ueki et al. [56] } \\
\text { Zhou et al. [55] }\end{array}$ \\
\hline Procalcitonin & No statistically significant change & Serum & Kawazoe et al. [14] \\
\hline Prealbumin & No statistically significant change & Serum & Kawazoe et al. [14] \\
\hline Nuclear Factor Kappa B & Decrease & Serum & Ueki et al. [56] \\
\hline High Mobility Group Box 1 (HMGB1) & Decrease & Serum & Ueki et al. [56] \\
\hline
\end{tabular}

with an anti-inflammatory effect. This study did not measure pro- or anti-inflammatory pathways [14]. The size and quality of the human studies was generally low, populations were heterogeneous, and most populations did not have severe illness. Anti-inflammatory effects were observed for potentially relevant inflammatory mediators in all studies, but none linked modulation of inflammation to clinical outcomes.

This is the first systematic review of the antiinflammatory effects of dexmedetomidine and clonidine that includes both human and animal studies. We included studies covering a wide range of inflammatory insults including animal sepsis, ARDS and ischemia models, human critical illness, and major surgical interventions. In animal studies, we also specifically described the dose of $\alpha 2$ agonist used and timing of administration to highlight relevance to human disease. The only other published systematic review described anti-inflammatory effects of perioperative dexmedetomidine as an adjunct to general anaesthesia and found significant reductions in perioperative IL-6, IL-8, TNF $\alpha$ concentrations, and post-operative IL-10. It also observed wide variation in the surgery studied and high statistical heterogeneity of effects between studies. However, the relevance to clinical outcomes was not included and only dexmedetomidine administered pre-operatively was reviewed [8]. Our review summarised the available animal data and also highlights the limited evidence for clonidine. Taken together, these data support a possible anti-inflammatory effect from $\alpha 2$ agonists but are inconclusive about the clinical importance of this finding.

There are several suggested mechanisms for an antiinflammatory/immune regulatory effect from $\alpha 2$ agonists. These include modulation of macrophage/ monocyte function through $\alpha 2$-receptor-mediated inhibition of apoptosis, central and peripheral $\alpha 2$-receptor agonist-mediated effects, direct or indirect central sympatholytic effects, stimulation of cholinergic antiinflammatory pathways, reduction in anxiety and stress, and indirect effects via anti-nociceptive and/or sedative effects. The studies included in our review do not enable the exact mechanisms to be conclusively elucidated, but 
those that included an antagonist $[4,18,20,25,29,30$, $33,35,38,44]$ mostly showed attenuation of $\alpha 2$ receptor agonist-mediated anti-inflammatory/immune regulatory effects suggesting a receptor-mediated effect is an important mechanism. This, however, was not a universal finding.

Whether anti-inflammatory effects are on a causative pathway to improved clinical outcomes in human critical illness is unproven. In the recent SPICE trial, which compared early dexmedetomidine based sedation with usual care (mostly propofol and/or midazolam) no overall mortality benefit was found and there was also no mortality benefit in a large sepsis sub-group (in whom an anti-inflammatory benefit may be most biological plausible) [15]. However, there were beneficial effects on both ventilation duration and delirium, and in a subgroup analysis the authors observed differences in the effect on mortality between younger (greater mortality with dexmedetomidine) and older (lower mortality with dexmedetomidine) patients for which the significance is uncertain. The mechanism of differential age-related effects of these agents is unexplained, but non-sedation related actions potentially, including immune/inflammatory modulation, might contribute. Further human studies are needed to explore whether the anti-inflammatory properties of $\alpha 2$-agonists are clinically important and whether differences between dexmedetomidine and clonidine might influence their modulation of clinical outcomes.

Our review has several limitations. Firstly, we used broad search terms to try and capture a wide range of studies, but we may have missed potentially relevant papers. Second, we cannot exclude publication bias especially for animal studies. Third, quantitative metaanalysis was not undertaken, because we did not consider this plausible or relevant for the identified literature; our data synthesis was therefore descriptive.

\section{Conclusion}

In conclusion, although the quality of animal and human studies is low, we have shown that $\alpha 2$ agonist drugs may potentially modify inflammatory and immune pathways in acute inflammatory conditions. Further work is required, especially in critically unwell humans, to explore mechanisms of action and whether these translate into improved patient outcomes.

\section{Supplementary information}

Supplementary information accompanies this paper at https://doi.org/10. 1186/s13054-019-2690-4.

Additional file 1. PRISMA Checklist.

Additional file 2. Summary of animal studies.

Additional file 3. Detailed description of animal studies.
Additional file 4. Summary of human studies.

Additional file 5. Detailed description of human studies.

\section{Abbreviations}

ABT: a-bungarotoxin; AKT: Protein kinase b; ALI: Acute lung injury; APZ: Atipamezole; ARDS: Acute respiratory distress syndrome;

CK18: Cytokeratin 18; CLP: Caecal ligation and puncture;

COX2: Cyclooxygenase 2; CRP: C Reactive protein; eNOS: Endothelial derived nitric oxide; GABA: Gamma-aminobutyric acid; HLA-DR: Human leukocyte antigen-DR isotype; HMGB1: High mobility group protein B1; ICU: Intensive

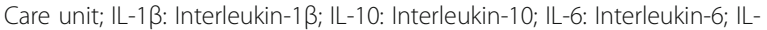
8: Interleukin-8; iNOS: Nitric Oxide Synthase; IRI: Ischaemia/reperfusion injury; LPS: Lipopolysaccharide; MIP-2: Macrophage inflammatory protein 2; MPO: Myeloperoxidase; MyD88: Myeloid differentiation primary response 88; NFkB: Nuclear factor kappa-light-chain-enhancer of activated B cells;

NGAL: Neutrophil gelatinase-associated lipocalin; nNOS: Neuronal nitric oxide; NO: Nitric Oxide; PGE2: Prostaglandin E2; Pi3k: Phosphoinositide 3-kinase;

PMN: Polymorphonuclear neutrophils; TLR4: Toll-like receptor 4;

TNFa: Tumour necrosis factor alpha; VEGF: Vascular endothelial growth factor; VILI: Ventilator-associated lung injury

\section{Authors' contributions}

CAF, ASR, TSW, and SAE wrote the manuscript. JKB reviewed the manuscript and made significant alterations. All authors read and approved the final manuscript.

\section{Funding}

No specific funding has to be declared.

Availability of data and materials

PubMed, the Cochrane library, and Medline databases

Ethics approval and consent to participate

Not applicable

Consent for publication

Not applicable

\section{Competing interests}

The authors declare that they have no competing interests.

\section{Author details}

${ }^{1}$ Critical Care Department, Royal Infirmary of Edinburgh, Edinburgh, UK. ${ }^{2}$ Department of Anaesthesia, Critical Care and Pain Medicine, University of Edinburgh, Edinburgh, UK. ${ }^{3}$ The Royal Infirmary of Edinburgh, NHS Lothian, Edinburgh, UK.

Received: 14 June 2019 Accepted: 28 November 2019 Published online: 11 December 2019

References

1. Gertler R, Brown HC, Mitchell DH, Silvius EN. Dexmedetomidine: a novel sedative-analgesic agent. Proc (Baylor Univ Med Cent). 2001;14(1):13-21.

2. Cruickshank M, Henderson L, MacLennan G, Fraser C, Campbell M, Blackwood B, et al. Alpha-2 agonists for sedation of mechanically ventilated adults in intensive care units: a systematic review. Health Technol Assess (Winchester, England). 2016;20(25):v-XX 1-117.

3. Chen $K$, Lu Z, Xin YC, Cai Y, Chen Y, Pan SM. Alpha-2 agonists for long-term sedation during mechanical ventilation in critically ill patients. Cochrane Database Syst Rev. 2015;1:Cd010269.

4. Zhang Z, Chen $\mathrm{K}, \mathrm{Ni} \mathrm{H}$, Zhang X, Fan H. Sedation of mechanically ventilated adults in intensive care unit: a network meta-analysis. Sci Rep. 2017;7:44979.

5. Skrobik Y, Duprey MS, Hill NS, Devlin JW. Low-dose nocturnal dexmedetomidine prevents ICU delirium. A randomized, placebo-controlled trial. Am J Respir Crit Care Med. 2018;197(9):1147-56.

6. Wang JG, Belley-Cote E, Burry L, Duffett M, Karachi T, Perri D, et al. Clonidine for sedation in the critically ill: a systematic review and meta-analysis. Critical care (London, England). 2017;21(1):75.

7. Cruz FF, Rocco PR, Pelosi P. Anti-inflammatory properties of anesthetic agents. Critical Care (London, England). 2017;21(1):67. 
8. Li B, Li Y, Tian S, Wang H, Wu H, Zhang A, et al. Anti-inflammatory effects of perioperative Dexmedetomidine administered as an adjunct to general anesthesia: a meta-analysis. Sci Rep. 2015;5:12342.

9. Sanders RD, Hussell T, Maze M. Sedation \& immunomodulation. Anesthesiol Clin. 2011;29(4):687-706.

10. Geloen A, Chapelier K, Cividjian A, Dantony E, Rabilloud M, May CN, et al. Clonidine and dexmedetomidine increase the pressor response to norepinephrine in experimental sepsis: a pilot study. Crit Care Med. 2013:41(12):e431-8.

11. Lankadeva YR, Booth LC, Kosaka J, Evans RG, Quintin L, Bellomo R, et al. Clonidine restores Pressor responsiveness to phenylephrine and angiotensin II in ovine sepsis. Crit Care Med. 2015;43(7):e221-9.

12. Morelli A, Sanfilippo F, Arnemann P, Hessler M, Kampmeier TG, D'Egidio A, et al. The effect of propofol and dexmedetomidine sedation on norepinephrine requirements in septic shock patients: a crossover trial. Crit Care Med. 2019;47(2):e89-95.

13. Pandharipande PP, Sanders RD, Girard TD, McGrane S, Thompson JL, Shintani AK, et al. Effect of dexmedetomidine versus lorazepam on outcome in patients with sepsis: an a priori-designed analysis of the MENDS randomized controlled trial. Critical Care (London, England). 2010;14(2):R38.

14. Kawazoe Y, Miyamoto K, Morimoto T, Yamamoto T, Fuke A, Hashimoto A, et al. Effect of dexmedetomidine on mortality and ventilator-free days in patients requiring mechanical ventilation with Sepsis: a randomized clinical trial. Jama. 2017;317(13):1321-8.

15. Shehabi Y, Howe BD, Bellomo R, Arabi YM, Bailey M, Bass FE, et al. Early Sedation with Dexmedetomidine in Critically III Patients. N Engl J Med. 2019;380(26):2506-2517.

16. Duan X, Coburn M, Rossaint R, Sanders RD, Waesberghe JV, Kowark A. Efficacy of perioperative dexmedetomidine on postoperative delirium: systematic review and meta-analysis with trial sequential analysis of randomised controlled trials. Br J Anaesth. 2018;121(2):384-97.

17. Chen Y, Miao L, Yao Y, Wu W, Wu X, Gong C, et al. Dexmedetomidine ameliorate CLP-induced rat intestinal injury via inhibition of inflammation. Mediat Inflamm. 2015;2015:918361.

18. Jiang L, Li L, Shen J, Qi Z, Guo L. Effect of dexmedetomidine on lung ischemiareperfusion injury. Mol Med Rep. 2014;9(2):419-26.

19. Uysal HY, Cuzdan SS, Kayiran O, Basar H, Fidanci V, Afyoncu E, et al. Preventive effect of dexmedetomidine in ischemia-reperfusion injury. J Craniofac Surg. 2012;23(5):1287-91.

20. Kong W, Kang K, Gao Y, Liu H, Meng X, Yang S, et al. Dexmedetomidine alleviates LPS-induced septic cardiomyopathy via the cholinergic antiinflammatory pathway in mice. Am J Transl Res. 2017;9(11):5040-7.

21. Hofer S, Steppan J, Wagner T, Funke B, Lichtenstern C, Martin E, et al. Central sympatholytics prolong survival in experimental sepsis. Crit Care. 2009;13(1):R11.

22. Wu Y, Liu Y, Huang H, Zhu Y, Zhang Y, Lu F, et al. Dexmedetomidine inhibits inflammatory reaction in lung tissues of septic rats by suppressing TLR4/NF-kappaB pathway. Mediat Inflamm. 2013;2013:562154.

23. Zhang J, Wang Z, Wang Y, Zhou G, Li H. The effect of dexmedetomidine on inflammatory response of septic rats. BMC Anesthesiol. 2015;15:68.

24. Shen J, Fu G, Jiang L, Xu J, Li L, Fu G. Effect of dexmedetomidine pretreatment on lung injury following intestinal ischemia-reperfusion. Exp Ther Med. 2013;6(6):1359-64.

25. Yang $\mathrm{CL}$, Tsai PS, Huang CJ. Effects of dexmedetomidine on regulating pulmonary inflammation in a rat model of ventilator-induced lung injury. Acta Anaesthesiol Taiwanica. 2008:46(4):151-9.

26. Yang CL, Chen CH, Tsai PS, Wang TY, Huang CJ. Protective effects of dexmedetomidine-ketamine combination against ventilator-induced lung injury in endotoxemia rats. J Surg Res. 2011;167(2):e273-81.

27. Sugita S, Okabe T, Sakamoto A. Continuous infusion of dexmedetomidine improves renal ischemia-reperfusion injury in rat kidney. J Nippon Med Sch. 2013;80(2):131-9

28. Loftus TJ, Thomson AJ, Kannan KB, Alamo IG, Millar JK, Plazas JM, et al. Clonidine restores vascular endothelial growth factor expression and improves tissue repair following severe trauma. Am J Surg. 2017;214(4):610-5.

29. Kang K, Gao Y, Wang SC, Liu HT, Kong WL, Zhang X, et al. Dexmedetomidine protects against lipopolysaccharide-induced sepsisassociated acute kidney injury via an alpha7 nAChR-dependent pathway. Biomed Pharmacother. 2018;106:210-6.

30. Tan F, Chen Y, Yuan D, Gong C, Li X, Zhou S. Dexmedetomidine protects against acute kidney injury through downregulating inflammatory reactions in endotoxemia rats. Biomed Rep. 2015;3(3):365-70.
31. Taniguchi T, Kidani Y, Kanakura H, Takemoto Y, Yamamoto K. Effects of dexmedetomidine on mortality rate and inflammatory responses to endotoxin-induced shock in rats. Crit Care Med. 2004;32(6):1322-6.

32. Taniguchi T, Kurita A, Kobayashi K, Yamamoto K, Inaba H. Dose- and timerelated effects of dexmedetomidine on mortality and inflammatory responses to endotoxin-induced shock in rats. J Anesth. 2008;22(3):221-8.

33. Xiang H, Hu B, Li Z, Li J. Dexmedetomidine controls systemic cytokine levels through the cholinergic anti-inflammatory pathway. Inflammation. 2014; 37(5):1763-70

34. Qiao H, Sanders RD, Ma D, Wu X, Maze M. Sedation improves early outcome in severely septic Sprague Dawley rats. Crit Care. 2009;13(4):R136.

35. Feng $X$, Guan $W$, Zhao $Y$, Wang C, Song M, Yao Y, et al. Dexmedetomidine ameliorates lipopolysaccharide-induced acute kidney injury in rats by inhibiting inflammation and oxidative stress via the GSK-3beta/Nrf2 signaling pathway. J Cell Physiol. 2019;234(10):18994-19009.

36. Xu L, Bao H, Si Y, Wang X. Effects of dexmedetomidine on early and late cytokines during polymicrobial sepsis in mice. Inflamm Res. 2013; 62(5):507-14.

37. Zhang JR, Lin Q, Liang FQ, Xie T. Dexmedetomidine attenuates lung injury by promoting mitochondrial fission and oxygen consumption. Med Sci Monit. 2019:25:1848-56.

38. Szelenyi J, Kiss JP, Puskas E, Selmeczy Z, Szelenyi M, Vizi ES. Opposite role of alpha2- and beta-adrenoceptors in the modulation of interleukin-10 production in endotoxaemic mice. Neuroreport. 2000;11(16):3565-8.

39. Filos KS, Panteli ES, Fligou F, Papamichail C, Papapostolou I, Zervoudakis G, et al. Clonidine pre-treatment prevents hemorrhagic shock-induced endotoxemia and oxidative stress in the gut, liver, and lungs of the rat. Redox Rep. 2012;17(6):246-51.

40. Miranda ML, Balarini MM, Bouskela E. Dexmedetomidine attenuates the microcirculatory derangements evoked by experimental sepsis. Anesthesiology. 2015;122(3):619-30.

41. Koca U, Olguner CG, Ergur BU, Altekin E, Tasdogen A, Duru S, et al. The effects of dexmedetomidine on secondary acute lung and kidney injuries in the rat model of intra-abdominal sepsis. ScientificWorldJournal. 2013;2013:292687.

42. Zhang Y, Ran K, Zhang SB, Jiang L, Wang D, Li ZJ. Dexmedetomidine may upregulate the expression of caveolin1 in lung tissues of rats with sepsis and improve the shortterm outcome. Mol Med Rep. 2017;15(2):635-42.

43. Zhang J, Peng K, Zhang J, Meng X, Ji F. Dexmedetomidine preconditioning may attenuate myocardial ischemia/reperfusion injury by down-regulating the HMGB1-TLR4-MyD88-NF-kB signaling pathway. PLoS One. 2017;12(2):e0172006.

44. Chen JH, Yu GF, Jin SY, Zhang WH, Lei DX, Zhou SL, et al. Activation of alpha2 adrenoceptor attenuates lipopolysaccharide-induced hepatic injury. Int J Clin Exp Pathol. 2015;8(9):10752-9.

45. Sezer $A$, Memis $D$, Usta $U$, Sut $N$. The effect of dexmedetomidine on liver histopathology in a rat sepsis model: an experimental pilot study. Ulus Travma Acil Cerrahi Derg. 2010;16(2):108-12.

46. Shi QQ, Wang H, Fang H. Dose-response and mechanism of protective functions of selective alpha-2 agonist dexmedetomidine on acute lung injury in rats. Saudi Med J. 2012;33(4):375-81.

47. Yeh YC, Wu CY, Cheng YJ, Liu CM, Hsiao JK, Chan WS, et al. Effects of dexmedetomidine on intestinal microcirculation and intestinal epithelial barrier in endotoxemic rats. Anesthesiology. 2016;125(2):355-67.

48. Wu RS, Wu KC, Huang CC, Chiang YY, Chen CC, Liao CL, et al. Different cellular responses of dexmedetomidine at infected site and peripheral blood of emdotoxemic BALB/c mice. Environ Toxicol. 2014;30(12):1416-22.

49. Chen C, Zhang Z, Chen K, Zhang F, Peng M, Wang Y. Dexmedetomidine regulates inflammatory molecules contributing to ventilator-induced lung injury in dogs. J Surg Res. 2014;187(1):211-8.

50. Gao S, Wang Y, Zhao J, Su A. Effects of dexmedetomidine pretreatment on heme oxygenase-1 expression and oxidative stress during one-lung ventilation. Int J Clin Exp Pathol. 2015;8(3):3144-9.

51. Kang SH, Kim YS, Hong TH, Chae MS, Cho ML, Her YM, et al. Effects of dexmedetomidine on inflammatory responses in patients undergoing laparoscopic cholecystectomy. Acta Anaesthesiol Scand. 2013:57(4):480-7.

52. Kim Y, Kang SH, Hong TH, Cho ML, Han HJ, Kwon SJ, et al. Effects of dexmedetomidine on the ratio of T helper 1 to $T$ helper 2 cytokines in patients undergoing laparoscopic cholecystectomy. J Clin Anesth. 2014; 26(4):281-5.

53. Tasdogan M, Memis D, Sut N, Yuksel M. Results of a pilot study on the effects of propofol and dexmedetomidine on inflammatory responses and intraabdominal pressure in severe sepsis. J Clin Anesth. 2009;21(6):394-400. 
54. Venn RM, Bryant A, Hall GM, Grounds RM. Effects of dexmedetomidine on adrenocortical function, and the cardiovascular, endocrine and inflammatory responses in post-operative patients needing sedation in the intensive care unit. Br J Anaesth. 2001;86(5):650-6.

55. Zhou H, Lu J, Shen Y, Kang S, Zong Y. Effects of dexmedetomidine on CD42a(+ )/CD14(+), HLADR(+)/CD14(+) and inflammatory cytokine levels in patients undergoing multilevel spinal fusion. Clin Neurol Neurosurg. 2017;160:54-8.

56. Ueki M, Kawasaki T, Habe K, Hamada K, Kawasaki C, Sata T. The effects of dexmedetomidine on inflammatory mediators after cardiopulmonary bypass. Anaesthesia. 2014;69(7):693-700.

57. Memis D, Hekimoglu S, Vatan I, Yandim T, Yuksel M, Sut N. Effects of midazolam and dexmedetomidine on inflammatory responses and gastric intramucosal pH to sepsis, in critically ill patients. Br J Anaesth. 2007;98(4):550-2.

\section{Publisher's Note}

Springer Nature remains neutral with regard to jurisdictional claims in published maps and institutional affiliations.

Ready to submit your research? Choose BMC and benefit from:

- fast, convenient online submission

- thorough peer review by experienced researchers in your field

- rapid publication on acceptance

- support for research data, including large and complex data types

- gold Open Access which fosters wider collaboration and increased citations

- maximum visibility for your research: over $100 \mathrm{M}$ website views per year

At BMC, research is always in progress.

Learn more biomedcentral.com/submissions 